\title{
Virtual Consumer Communities for Innovation: A Cross-Cultural Perspective
}

\author{
Lina Fogt Jacobsen, Marcia D. De Barcellos, Alexia Hoppe \& Liisa \\ Lähteenmäki
}

To cite this article: Lina Fogt Jacobsen, Marcia D. De Barcellos, Alexia Hoppe \& Liisa Lähteenmäki (2019) Virtual Consumer Communities for Innovation: A Cross-Cultural Perspective, Journal of International Consumer Marketing, 31:2, 98-114, DOI: 10.1080/08961530.2018.1481803

To link to this article: https://doi.org/10.1080/08961530.2018.1481803

册 Published online: 07 Apr 2019.

Submit your article to this journal $\widetilde{ }$

Џll Article views: 164

Q View related articles ¿

View Crossmark data ¿ᄌ 


\title{
Virtual Consumer Communities for Innovation: A Cross-Cultural Perspective
}

\author{
Lina Fogt Jacobsen ${ }^{a}$, Marcia D. De Barcellos ${ }^{\mathrm{b}}$, Alexia Hoppe ${ }^{\mathrm{b} *}$ and Liisa Lähteenmäki ${ }^{\mathrm{a}}$ \\ aDepartment of Management, Mapp Centre - Research on Value Creation in the Food Sector, Aarhus University, Aarhus, Denmark; \\ ${ }^{b}$ Department of Administrative Sciences, Federal University of Rio Grande do Sul, Porto Alegre, Brazil
}

\section{ABSTRACT}

This study investigates the moderating role of culture in the motivation of consumers' intention to participate in virtual communities for product innovation. Surveys were conducted in Denmark $(n=1045)$ and Brazil $(n=617)$. Findings show that relatedness is the strongest driver of consumers' intended interaction, but the importance of group vs. company relatedness differs between countries. Possible beneficial outcomes drive consumers in both countries. The main implication realized from this study is the cross-country moderation, as to the importance of the two dimensions of relatedness, which is likely to be rooted in the individualism-collectivism dimension of culture.

\section{KEYWORDS}

Virtual communities; individualism-collectivism; product innovation; consumer integration; cross-cultural

\section{Introduction}

To stay competitive, companies must constantly develop successful products of superior value to consumers (Griffin and Page 1996; Henard and Szymanski 2001; Cooper and Kleinschmidt 2007). This requires an understanding of the market, which implies information from consumers to be used in innovation (Narver and Slater 1990; Poolton and Barclay 1998). Recognizing that openness toward external actors is a requirement for successful innovation (Chesbrough 2003; Dahlander and Gann 2010), the role of consumers as a valuable source for innovation is emphasized (Lüthje 2004; Poetz and Schreier 2012; Von Hippel, de Jong, and Flowers 2012; Nishikawa, Schreier, and Ogawa 2013). Some companies therefore have consumers collaborate in their innovation process (Greer and Lei 2012). Such integration of consumers has the potential to boost companies' innovation performance (Troy, Hirunyaawipada, and Paswan 2007; Witell et al. 2010). In this regard, virtual communities (VCs) are increasingly emphasized as a tool for continuous interaction with consumers (Fuchs and Schreier 2011; Schreier, Fuchs, and Dahl 2012). Much research on the influence of consumer motivation for interacting in such communities has been conducted (e.g., Nambisan 2002; Füller 2010; Porter et al. 2011; Poetz and Schreier 2012). Whereas most of this research treats motivation as homogenous, some studies recognize the potential differences in motivation between individuals. For example, David and Shapiro (2008) suggest that motivations are heterogeneous and that individuals can be clustered based on differences in their motivation for participating in open-source projects. Other studies on open-source projects conclude that individuals are motivated by internal and external motivation factors to various extents (Hars and $\mathrm{Ou}$ 2002; Oreg and Nov 2008). Still, only limited research addresses the potential differences in drivers of participation in various kinds of VCs that may exist between consumers from different cultures (e.g., Madupu and Cooley 2010; Muk, Chung, and Kim 2014). One exception is a study by Madupu and Cooley (2010) concluding that consumers' motivation for joining online brand communities differs between individualistic and collectivistic cultures. Acknowledging the potential heterogeneity in motivation that may be rooted in culture, this study is among the first to 
investigate the cross-cultural differences in consumers' motivation to engage in VCs for product innovation in particular. More specifically, by introducing individualism-collectivism as a cultural factor differing between countries, this study extends existing research on consumer motivation for VC interaction with an innovation purpose. Country is therefore used to represent the cultural individualism-collectivism dimension.

The findings generate ideas for the scientific community in marketing and innovation as well as for practitioners interested in implementing and managing VCs for product innovation in different cultures. The aim of this study is to investigate (1) how motivation factors, rooted in the need for relatedness, competence, and autonomy, influence behavioral interaction intention in a VC aiming at product innovation, and (2) how these relationships are moderated by countries differing on the individualism-collectivism dimension.

The remainder of this article first provides a background presenting the concept of VCs, human motivation, and the cultural individualism-collectivism dimension, including the derivation of the hypothesized relationships. The method is then explained followed by the model testing in the results section. Afterwards, the results are discussed, and finally the limitations of the study, future research potential, and implications are addressed.

\section{Background}

\section{VC in innovation}

VCs can be used to integrate consumers in the innovation process (Nambisan 2002; Fuchs and Schreier 2011; Schreier, Fuchs, and Dahl 2012) because VCs have the potential to create an ongoing dialog between consumers and companies with a view to knowledge sharing (Sawhney, Verona, and Prandelli 2005). They "comprise a large, loosely knit, and geographically distributed group of individuals engaged in a shared practice of problem solving, knowledge exchange, or social interactions that mainly occur through computer-mediated communications" (Hsu, Chiang, and Huang 2012, 73). Several studies have been conducted on individual characteristics and motivation associated with voluntarily engaging in idea generation in various categories such as open-source projects on software and content (Hars and Ou 2002; Hertel, Niedner, and Herrmann 2003; Von Krogh and Von Hippel 2006; Nov 2007; David and Shapiro 2008; Oreg and Nov 2008; Schroer and Hertel 2009; Bitzer and Geishecker 2010; von Krogh et al. 2012), VCs of practice (Ardichvili, Page, and Wentling 2003; Daugherty et al. 2005; Wasko and Faraj 2005, 2000; Ardichvili 2008) as well as user innovation/consumer integration communities (Franke and Shah 2003; Jeppesen and Frederiksen 2006; Nambisan and Baron 2009; Füller 2010; Porter et al. 2011).

Within the various types of VCs, different motivation factors for engagement have been studied: learning (von Hippel 2007; Wiertz and de Ruyter 2007), recognition from peers and companies (Jeppesen and Molin 2003; Jeppesen and Frederiksen 2006; Füller, Jawecki, and Mühlbacher 2007; von Hippel 2007), and empowerment (Füller et al. 2009). This extensive research indicates that many different perspectives are important in consumers' motivation for engaging in VCs.

Generally, human motivation is rooted in a basic psychological need for competence, autonomy, and relatedness (Ryan and Deci 2000), and to satisfy these needs, individuals may engage in various behaviors including social interaction (Patrick et al. 2007). Despite being based on common needs (Ryan and Deci 2000), behavioral motivation may, at a more detailed level, differ across cultures (e.g., Hofstede 1983b). Therefore, it is important to understand the role of culture to optimize the management of marketing and innovation activities (Hofstede 1983a; Nakata and Sivakumar 1996; Kumar 2014; Thompson and Chmura 2015). Cultures differ on various dimensions characterizing society (Hofstede 1983b, 2001), but the focus of this study is on the individualism-collectivism dimension. This dimension refers to the relationship between individuals, which is likely to be important when discussing VCs, as they consist of groups of people. 


\section{Motivation rooted in relatedness}

The need for relatedness is "the desire to feel connected to others" (Ryan and Deci 2000, 231). The feeling of belonging to a group is an essential human desire (Ashforth, Harrison, and Corley 2008), and joining social networks and interacting with companies as well as other consumers offer an opportunity to forge social bonds (Achrol and Kotler 1999; Etgar 2008). VCs can act as places to belong to and they provide the opportunity to relate to others with similar interests (Kurikko and Tuominen 2012).

Relational capital implies that individuals have a strong identification with and trust in a network (Wasko and Faraj 2000; Chang and Chuang 2011). As a consequence, identification, trust, and relatedness are concepts that are hard to separate. People act in congruence with their identity (Shavitt, Torelli, and Wong 2009; Oyserman 2015), and VC interaction is likely to occur only if consumers consider the VC congruent with their identity.

Identification with the $\mathrm{VC}$, and thereby the motivation to engage, may differ depending on the VC being either consumer hosted or company hosted (Lee and Chang 2011; Teichmann et al. 2015). When a company hosts a VC for product innovation purposes, the participating consumer may perceive him-/herself as part of the VC group representing consumers and/or part of the innovation team representing the company. Hutter, Nketia, and Füller (2017) distinguish between sense of organizational community and sense of VC. Sense of organizational community is "an individual's feeling of relationship to the organizational community or personal knowledge about belonging to an entity inclusive of others" (Hutter, Nketia, and Füller 2017, 356), whereas sense of VC is "the feeling of membership, belonging, and attachment to a virtual group that exists online" (Hutter, Nketia, and Füller 2017, 356). In our study, two areas of relatedness are considered relevant: relatedness to the $\mathrm{VC}$ as a group (i.e., group relatedness) and relatedness to the VC-hosting company (i.e., company relatedness).

\section{Group relatedness}

According to the social identity theory, consumers identify with an in-group that they believe to be similar to themselves. At the same time they separate themselves from outgroups considered to be different (Bagozzi and Dholakia 2006). The ability to identify with VCs as "the degree to which the member sees him- or herself as part of the group" (Casaló, Flavián, and Guinalíu 2010, 900) depends on the development of the in-group distinction. The feeling of belonging to the group develops emotional involvement (Bagozzi and Dholakia 2006). A consumer's identification with a particular VC group thus reflects the strength of his/her feeling of belonging to the members in the VC group (Algesheimer, Dholakia, and Herrmann 2005).

Identification with the VC group is an antecedent of community engagement which is likely to lead to VC participation (Algesheimer, Dholakia, and Herrmann 2005; Casaló, Flavián, and Guinalíu 2010). Connecting with other relevant persons is one of the benefits of participating in VCs for innovative purposes (Nambisan and Baron 2009). The shared identity positively influences the we-intentions whereby consumers intend to "work jointly with others or to see it jointly with the others that a certain state or event comes about" (Bagozzi and Dholakia 2006, 1103). Community identification increases consumer interaction both directly and through its influence on community trust (Hsu, Chiang, and Huang 2012). Also Chang and Chuang (2011) emphasize trust and identification as relational aspects supporting consumers' knowledge contribution in VCs. Still, Nambisan (2002) proposes the relative importance between social and individual identity to differ, depending on the consumer's role in the innovation process: social identity (i.e., perceiving oneself as member of the group) dominates in VCs aiming at product support, but is overruled by individual identity (i.e., perceiving oneself as an independent agent of innovation) in VCs focusing on product innovation.

Thus, the following hypothesis is proposed:

Hypothesis 1: Perceived group relatedness increases intended VC interaction behavior 


\section{Company relatedness}

O'Reilly and Chatman (1986) treat identification as a foundation for psychological commitment to an organization and relate organizational identification to desire for affiliation. Consumers' identification with companies is increasingly sought by marketing managers as it can help establish a long-term relationship with consumers (Bhattacharya and Sen 2003). Individuals who identify with the company, act as part of it (Ashforth, Harrison, and Corley 2008) and will be more inclined to seek contact with the company and collaborate with its members (Dutton, Dukerich, and Harquail 1994). These individuals are also more likely to be productive and contribute to organizational aims to a larger extent (Lee 1971; Bhattacharya and Sen 2003). As O’Reilly and Chatman (1986) conclude, commitment based on identification is strongly related to prosocial behavior (i.e., employee behavior benefiting the organization without being a direct part of the job description and not expected by the organization).

Individuals are likely to support companies perceived as congruent with their own identity (Ashforth and Mael 1989) and to establish a relationship resulting in company-directed behavior (Bhattacharya and Sen 2003). Identification with the company yields an expectation of fairness in the collaboration, and this expectation makes individuals likely to contribute (Franke, Keinz, and Klausberger 2013). For company hosted VCs integrating consumers in innovation, the perceived fairness of the collaboration is especially important (Franke, Keinz, and Klausberger 2013). Organizational identification implies that the consumer will be more likely to interact in a VC to help the company with its innovation purpose. The following hypothesis is therefore proposed:

Hypothesis 2: Perceived company relatedness increases intended VC interaction behavior

\section{Motivation rooted in competence}

The need for feeling competent relates to the capability of mastering any required behavior (Van den Broeck et al. 2010). In order to feel competent in a domain, a person has to understand and possess the relevant skills to perform the behavior (Ryan and Deci 2000; Patrick et al. 2007). Perceived competence creates motivation to test and extend one's capabilities, whereas lack of perceived competence is likely to decrease motivation (Deci and Ryan 2000; Van den Broeck et al. 2010). Competence is divided into objective competence, which is an external evaluation, and subjective competence (i.e., perceived competence), which is the individual's own perception of his/her skills and abilities (Harter 1982; Proksch, Orth, and Cornwell 2015). Focus in this study is on perceived competence, which is the individual's own perception of his/ her skills and abilities (Harter 1982; Proksch, Orth, and Cornwell 2015).

Perceived competence has been investigated as a motivation factor (e.g., Harter 1982; Klint and Weiss 1987). In consumer behavior, the way people evaluate their own competences is often addressed as self-efficacy, which is a factor affecting human motivation and behavior (e.g., Bandura 1982; Kim, Kim, and Hwang 2008). The individual is motivated by reasons corresponding to his/her perceived competences: individuals are likely to continue a behavior if they feel competent because they are motivated to demonstrate and improve their skills (Harter 1978; Klint and Weiss 1987). In the area of product innovation as a collaboration between company and consumers, this would imply that consumers who feel competent and skilled in the domain of interest are more motivated to engage in the product innovation activities. The following hypothesis is therefore proposed:

\footnotetext{
Hypothesis 3: Perceived skills increase intended VC interaction behavior
}

\section{Motivation rooted in autonomy}

Autonomy can be defined as feeling 'volitional in one's actions, to fully and authentically endorse one's behaviors, and to act as the originator of one's own behavior' (Patrick et al. 2007, 434). This definition implies that the individual feels a psychological freedom and perceives his/her behavior to be self-determined (Ryan and Deci 2000). In consumer behavior, autonomy can be 
reflected in the feeling of empowerment in influencing the outcomes of a behavior. For consumer engagement in product innovation, features supporting integrity and autonomy are considered to be crucial for the participating consumers' psychological well-being (Mosteller and Mathwick 2014). Consumers engage in product innovation based on their own decisions grounded in a preference for controlling their environment and influencing the final, future product outcome (Etgar 2008). Füller et al. (2009)describe how consumers can obtain the feeling of empowerment (i.e., perceived influence on product design and decision-making) by engaging in online innovation of products. Consumers take an active role in creating product benefits for themselves. However, consumers may not do this for individual benefits in particular, but aim at "transcending their personal sphere to acknowledge the welfare of a wider society and contribute to the common good" (Martinez-Canas et al. $2016,8)$. By engaging in VCs for product innovation, consumers may feel that they contribute to higher societal well-being. The following hypothesis is proposed:

Hypothesis 4: Perceived outcome benefits increase VC interaction behavior

\section{The moderating effect of culture}

Culture based on nationality has been recognized as a powerful influencer in the area of marketing and consumer behavior (e.g., Aaker and Williams 1998). Culture can, in part, explain why individuals differ in their characteristics and motivation for different behaviors (e.g., Lynn and Gelb 1996; Hofstede 1983b; Hornik and Tupchiy 2006; Abbasi et al. 2015; Thompson and Chmura 2015) and plays a big role in consumer behavioral relationships (e.g., Luna and Gupta 2001; Jin, Park, and Kim 2008; Park, Jun, and Lee 2015). Culture is "the collective programing of the mind that distinguishes one group or category of people from another" (Hofstede and McCrae 2004, 58). Countries differ in culture on various dimensions, one of which is 'individualism-collectivism' which refers to the degree of integration of individuals into groups (Hofstede 1991, 2001). This may therefore be highly relevant when focusing on groups of individuals in an online environment such as VCs consisting of consumers. In individualistic cultures, ties between people are loosely knit, and individuals focus largely on themselves and people very close to them. In collectivistic cultures, ties between people are strong, and the group is in focus rather than the individual. People are integrated into groups, and the group protects the individual in return for loyalty (Hofstede 1991; Hofstede and McCrae 2004).

In terms of consumer integration in product innovation, the cultural dimension of individualism-collectivism may influence the relationship between the specific motivation factors and intention to participate. Particularly for relatedness, the group aspect may play a stronger role in collectivistic cultures where the goals of the group are prioritized above the goals of the individual (Hofstede 1991). Individuals are more inclined to share information with their in-group in collectivistic cultures (Chow, Deng, and Ho 2000), and this tendency is present in the online environment as well (Madupu and Cooley 2010). On the other hand, the individual's own relatedness with the company may be more dominant in individualistic cultures where the individual is prioritized above the group. These individuals have a stronger focus on self-interest and on their own uniqueness (Markus and Kitayama 1991).

Furthermore, the priority of the group-related goals compared to the individual goals (Hofstede 1991, 2001) and concern for the well-being of society as a whole may be stronger in collectivistic cultures (Sorensen and Oyserman 2009). Therefore, the perceived outcome benefits for the market and consumers in general are likely to be more important in a collectivistic culture compared to an individualistic one. The following hypotheses are proposed:

Hypothesis 5a: The relationship between group relatedness and intended $\mathrm{VC}$ interaction behavior is stronger in a collectivistic culture compared to an individualistic culture.

Hypothesis 5b: The relationship between company relatedness and intended VC interaction behavior is stronger in an individualistic culture compared to a collectivistic culture. 


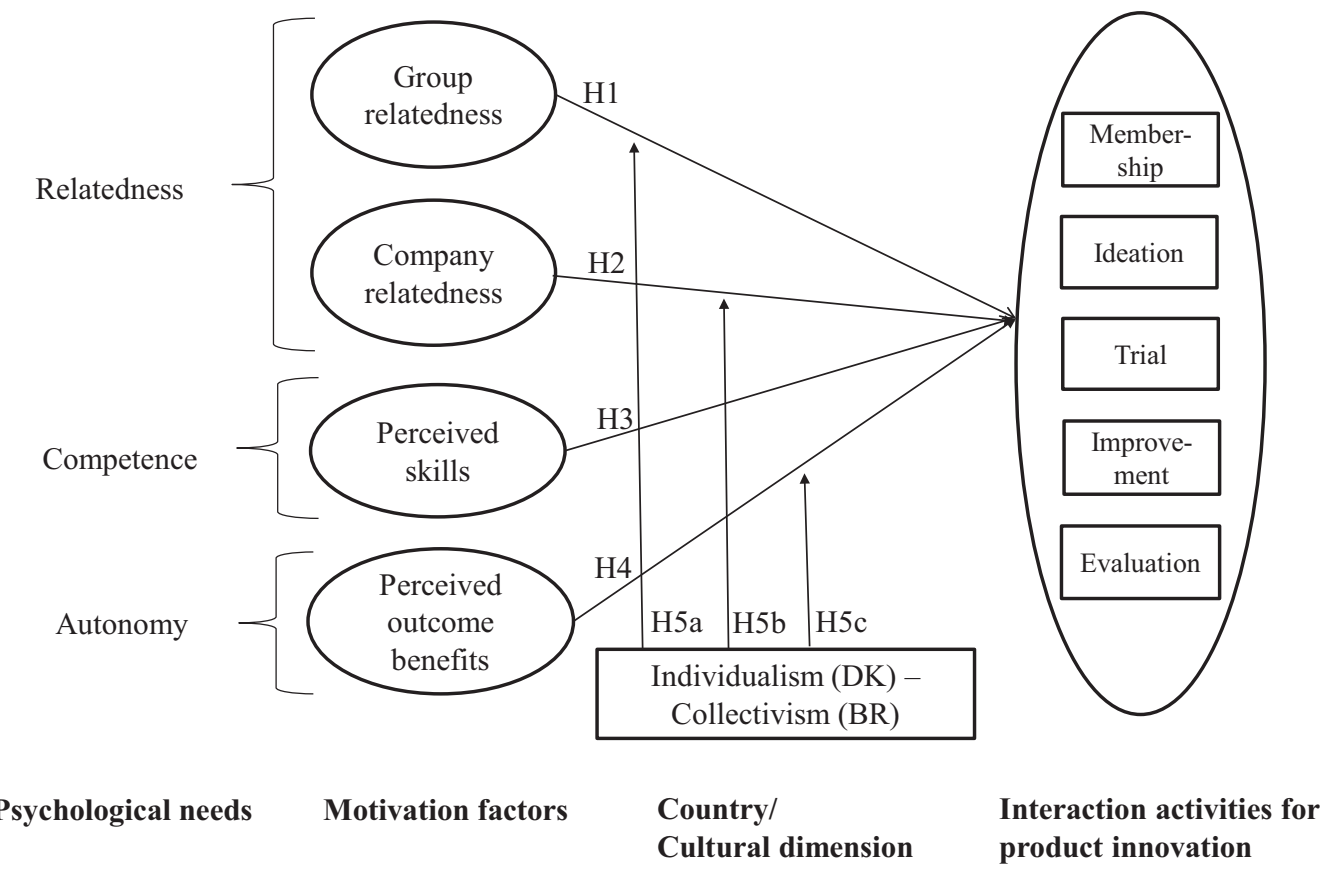

Figure 1. The suggested relationships.

Hypothesis 5C: The relationship between perceived outcome benefits and intended interaction behavior is stronger in a collectivistic culture compared to an individualistic culture.

Figure 1 presents the suggested relationships.

\section{Method}

\section{Respondents and questionnaire procedure}

The data were collected in Denmark $(n=1045)$ and Brazil $(n=617)$. Denmark represents a culture high in individualistic values, whereas Brazil represents a culture relatively low in individualistic values (Hofstede 1991, 2001). More specifically, Denmark is described as an individualistic society where individuals mainly focus on themselves and their closest relatives, whereas Brazil is described as a society where individuals are part of strong and cohesive groups where others are helped in return for loyalty. In Denmark, trust is assumed without knowing the counterpart, but in Brazil trust must be established by building personal relations before conducting business (Hofstede-Insights 2018). Individualistic values combined with high trust in Denmark and collectivistic values combined with strong group cohesion in Brazil allow comparison of consumers from two different cultures on their willingness to engage in co-creation activities and how this willingness is related to different actors, namely industry and fellow consumers.

In Denmark, data were obtained through an online survey; respondents were selected through a market agency. The distribution between females and males was $50.4 \%$ and $49.6 \%$, respectively, and the average age was 44 years. In Brazil, data were collected through face-to-face surveys. The sample was collected in parks and farmers' markets by interviewers from an academic research center. Females made up 55.6\% of the sample whereas $44.4 \%$ were males. The average age was 37 years. The data collection methods were chosen to obtain representative samples in each country in order to be able to compare the groups.

Respondents were introduced to the concept of a $\mathrm{VC}$ aimed at designing a weight management food product together with a company (figure 2). The idea was to choose a specific product that most consumers could relate to. Confirming its relevance, the data revealed that $67.1 \%$ of the Danish respondents and $63.3 \%$ of the Brazilian respondents actively tried to lose or maintain their weight. Furthermore, considering the weight management food product to be a socially responsible product, the social justice aspect of the product is likely to make it more relevant for consumers to engage in product innovation 


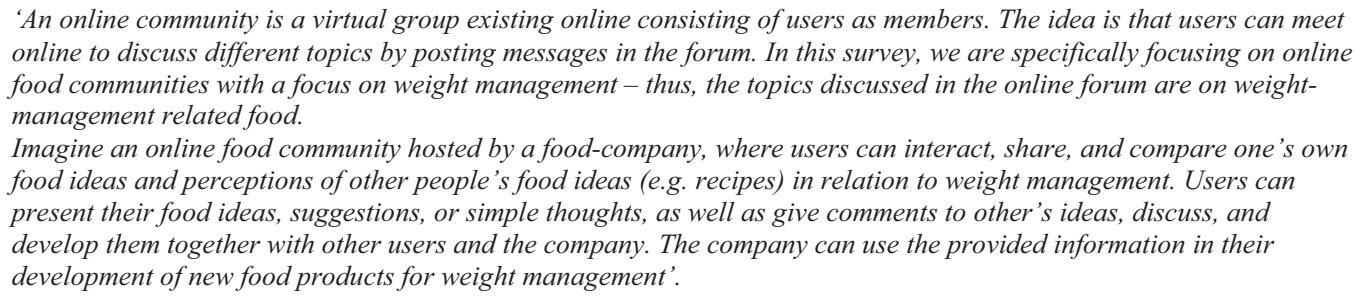

Figure 2. Description of virtual community.

(Martinez-Canas et al. 2016). Respondents were then asked about the motivation factors as well as their intention to engage in different interaction activities. Demographic questions were asked at the end.

\section{Measurement model}

All variables were treated as latent constructs and measured by multiple items (see table 1). Furthermore, they were adapted to the food domain. Items representing perceived skills, group relatedness, company relatedness, and perceived outcome benefits were measured using a 7-point Likert scale ranging from 'strongly disagree' to 'strongly agree'. Items underlying intended interaction activity were also measured on a 7-point scale spanning from 'not interested at all' to 'very interested'. Both the Danish and the Brazilian version of the questionnaire went through back-translation to ensure that their meaning remained as intended.

Items measuring 'perceived skills' were adapted from the scale on perceived cooking skills developed by Hartmann, Dohle, and Siegrist (2013). Considering their irrelevance in the Danish and the Brazilian food culture, two items were removed from the original scale, and one item was added. Four items measuring 'group relatedness' were based on the scale by Chiu, Hsu, and Wang (2006) for measuring identification with a VC as a group of people. Two items measuring 'company relatedness' were developed for this study to address identification with and trust in the company, which are normally highly correlated (Franke, Keinz, and Klausberger 2013). Items measuring 'perceived outcome benefits' were also developed for this study to reflect the tangible beneficial outcomes for the food market and consumers in general. Five items measuring intended interaction activities were developed. These items represented possible interaction activities considered relevant for product innovation in a VC context. Negatively phrased questions were reversed for further analysis.

\section{Results}

In the following, the steps carried out in the data analysis are presented. First, reliability as well as convergent and discriminant validity of the measurement model were examined in order to ensure that items consistently measure constructs as intended (Anderson and Gerbing 1988). This was followed by a confirmatory factor analysis (CFA) of each sample. Second, the invariance across groups was examined. Both configural and metric invariance were tested. Third, structural equation modeling (SEM) was conducted as a multi-group analysis to test the moderating effect of country on the suggested relationships (H5). Fourth, Hypotheses 1-4 were tested for the individual country samples.

\section{Reliability and validity of the measurement model}

The analysis was conducted in AMOS22. Results on reliability and validity of the measurement model (table 1) show an acceptable goodness-offit in both the Danish and the Brazilian sample $\left(\mathrm{CFI}_{\mathrm{DK}}=0.976, \quad \mathrm{CFI}_{\mathrm{BR}}=0.968, \quad \mathrm{NFI}_{\mathrm{DK}}=0.968\right.$, $\mathrm{NFI}_{\mathrm{BR}}=0.954$, RMSEA ranging from 0.052 to 0.061 , and $\chi^{2}$ over degrees of freedom (df) between 3.84 and 3.27). For each construct in both samples, the composite reliability (CR) and the average variance extracted (AVE) were computed to check the reliability of each scale (Hair et al. 2010). All values for CR and AVE were 


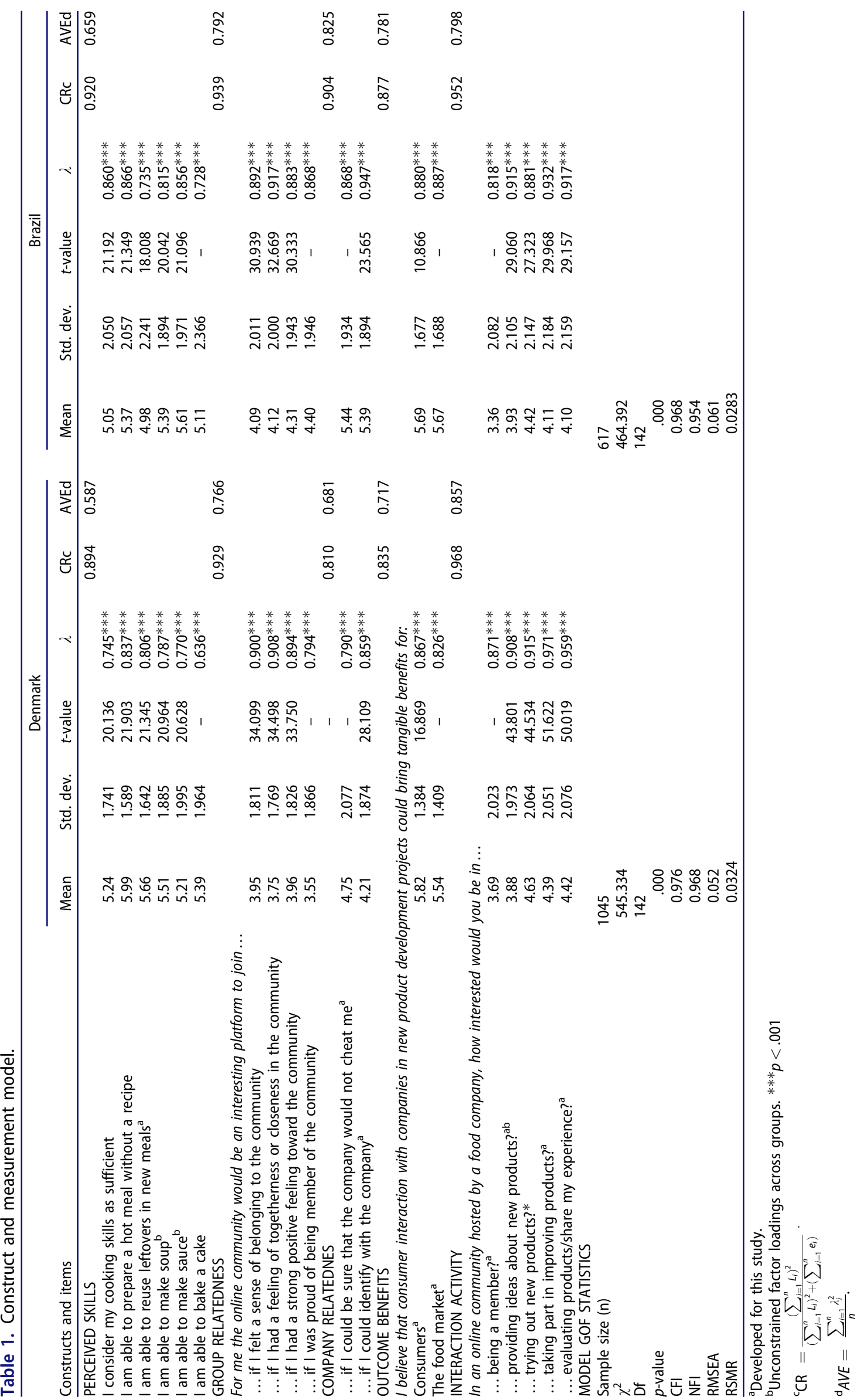


Table 2. Correlations between constructs.

\begin{tabular}{|c|c|c|c|c|c|c|c|c|c|c|}
\hline \multirow[b]{2}{*}{ Constructs } & \multicolumn{4}{|c|}{ Denmark } & \multirow[b]{2}{*}{5} & \multicolumn{4}{|c|}{ Brazil } & \multirow[b]{2}{*}{5} \\
\hline & 1 & 2 & 3 & 4 & & 1 & 2 & 3 & 4 & \\
\hline Skills(1) & $0.766^{\mathrm{a}}$ & 0.135 & 0.234 & 0.207 & 0.211 & $0.812^{\mathrm{a}}$ & 0.288 & 0.225 & 0.068 & 0.228 \\
\hline Group relatedness (2) & & $0.875^{\mathrm{a}}$ & 0.787 & 0.293 & 0.646 & & $0.890^{\mathrm{a}}$ & 0.587 & 0.211 & 0.587 \\
\hline Company relatedness (3) & & & $0.825^{\mathrm{a}}$ & 0.394 & 0.772 & & & $0.908^{\mathrm{a}}$ & 0.317 & 0.506 \\
\hline Outcome benefits (4) & & & & $0.847^{\mathrm{a}}$ & 0.454 & & & & $0.884^{\mathrm{a}}$ & 0.258 \\
\hline Interaction (5) & & & & & $0.926^{\mathrm{a}}$ & & & & & $0.893^{\mathrm{a}}$ \\
\hline
\end{tabular}

Table 3. Measurement invariance across groups.

\begin{tabular}{|c|c|c|c|c|c|c|c|c|}
\hline Invariance model & $\chi^{2}$ & Df & $\chi^{2} / d f$ & CFI & $\mathrm{NFI}$ & RMSEA & SRMR & $\mathrm{AIC}$ \\
\hline Configural & 1009.786 & 284 & 3.556 & 0.973 & 0.963 & 0.039 & 0.0324 & 1201.786 \\
\hline Full metric & 1051.907 & 298 & 3.530 & 0.972 & 0.962 & 0.039 & 0.0324 & 1215.907 \\
\hline Partial metric & 1023.346 & 295 & 3.469 & 0.973 & 0.963 & 0.039 & 0.0285 & 1197.874 \\
\hline \multicolumn{9}{|c|}{ Assuming configural model to be correct: } \\
\hline
\end{tabular}

above the cutoff points of 0.8 and 0.5 , respectively, supporting the scale reliability. Measurement models for both samples revealed acceptable levels of convergent validity with all factor loadings above 0.6 with $p<.01$ (Anderson and Gerbing 1988).

Based on Fornell and Larcker (1981), discriminant validity was assessed for the model in both samples (table 2). The square root of AVE of any two constructs should be larger than the correlation coefficient between the constructs, and the results indicated that all pairs of reflective constructs fulfilled this requirement emphasizing the support of discriminant validity. Overall, the suggested constructs have a satisfactory level of fit as well as reliability and convergent and discriminant validity in both the Brazilian and the Danish sample.

\section{Measurement model invariance across groups}

Invariance in factor structure across the Danish and Brazilian samples was checked. The fit of the configural invariance model was good (table 3) indicating the same factor structure to be appropriate in both samples. The metric invariance was then tested by constraining each factor loading to be equal across samples. This full metric constrained model was compared with the configural invariance model. The results showed a significant difference in the model between the two samples (increase in $\chi^{2}$ from 1009.786 to 1051.907 with $p \leq .001$ ) indicating that the same factor structure is inappropriate across samples.
This means that some factor loadings differ significantly between groups and should be allowed to variate for further analysis. To identify these factor loadings, a number of partial invariance tests were conducted. Each specific factor loading was constrained to be equal across samples, whereas the remaining factor loadings were kept as variable. Each of the partially constrained models was compared to the configural invariance model, and the results indicate that three of the factor loadings were significantly different across samples and were therefore allowed to vary. After unconstraining the selected factor loadings in a partial metric invariance model, results showed an insignificant difference between the model in the two samples (increase in $\chi^{2}$ from 1009.786 to 1023.346 with $p=.258$ ) indicating a similarity in factor structure across the Brazilian and Danish samples (see table 3). The analysis now supported configural and partial invariance.

\section{Model testing and cultural moderating effects}

In order to test the significance of the structural differences between Denmark and Brazil, a multigroup SEM was conducted. First, based on the partial metric model established before, an unconstrained structural model was established in which all structural relationships were allowed to vary across samples. This model had an acceptable fit $($ RMSEA $=0.039$, CFI $=0.973)$. Second, a fully constrained structural model, in which all structural relationships were invariant, was 
Table 4. Overview of significance of cross-country effects.

\begin{tabular}{|c|c|c|c|c|c|c|c|c|c|}
\hline Model & Constraint & $\chi^{2}$ & df & CFI & RMSEA & $\Delta \chi^{2}$ & $\Delta \mathrm{df}$ & $\begin{array}{c}p \text {-value } \\
\text { assuming } \\
\text { unconstrained } \\
\text { as correct }\end{array}$ & $\begin{array}{c}\text { Significant } \\
\text { difference } \\
\text { between DK } \\
\text { and BR }\end{array}$ \\
\hline Unconstrained & & 1023.346 & 295 & 0.973 & 0.039 & - & - & - & \\
\hline $\begin{array}{l}\text { full constrained } \\
\text { Constraints on: }\end{array}$ & & 1082.491 & 299 & 0.971 & 0.040 & 59.145 & 4 & .000 & Yes \\
\hline $\begin{array}{l}\text { Model 1: group } \\
\quad \text { relatedness } \rightarrow \\
\quad \text { Interaction }\end{array}$ & b1_1=b1_2 & 1043.815 & 296 & 0.972 & 0.039 & 20.469 & 1 & .000 & Yes \\
\hline $\begin{array}{l}\text { Model 2: company } \\
\quad \text { relatedness } \rightarrow \\
\quad \text { interaction }\end{array}$ & b2_1 = b2_2 & 1059.820 & 296 & 0.972 & 0.039 & 36.474 & 1 & .000 & Yes \\
\hline $\begin{array}{l}\text { Model 3: skills } \rightarrow \\
\quad \text { interaction }\end{array}$ & b3_1=b3_2 & 1023.657 & 296 & 0.973 & 0.038 & 0.311 & 1 & .5770 & No \\
\hline $\begin{array}{l}\text { Model 4: outcome } \\
\quad \text { benefits } \rightarrow \\
\text { interaction }\end{array}$ & b4_1=b4_2 & 1029.988 & 296 & 0.973 & 0.039 & 6.642 & 1 & .0099 & Yes \\
\hline
\end{tabular}

Table 5. Overall SEM testing hypothesized relationships for individual groups.

\begin{tabular}{|c|c|c|c|c|c|}
\hline \multirow{2}{*}{\multicolumn{2}{|c|}{ Structural relationships }} & \multicolumn{2}{|c|}{ Denmark } & \multicolumn{2}{|c|}{ Brazil } \\
\hline & & $\mathrm{b}$ & $t$-value & $\mathrm{b}$ & $t$-value \\
\hline \multicolumn{2}{|c|}{ Group relatedness $\rightarrow$ interact } & $0.115^{*}$ & 2.457 & $0.430 * * *$ & 9.622 \\
\hline \multicolumn{2}{|c|}{ Company relatedness $\rightarrow$ Interact } & $0.604 * * *$ & 10.949 & $0.221^{* * *}$ & 4.769 \\
\hline \multicolumn{2}{|c|}{ Skills $\rightarrow$ interact } & $0.026^{\text {n.s. }}$ & 1.417 & $0.034^{\text {n.s. }}$ & 1.417 \\
\hline \multicolumn{2}{|c|}{ Outcome benefits $\rightarrow$ interact } & $\begin{array}{l}0.179^{* * *} \\
\text { del fit }\end{array}$ & 6.525 & $0.093^{*}$ & 2.482 \\
\hline CMIN & 1023.657 & & & & \\
\hline Df & 296 & & & & \\
\hline$p$-value & .000 & & & & \\
\hline CMIN/df & 3.458 & & & & \\
\hline $\mathrm{CFI}$ & 0.973 & & & & \\
\hline NFI & 0.963 & & & & \\
\hline RMSEA & 0.038 & & & & \\
\hline SRMR & 0.0286 & & & & \\
\hline
\end{tabular}

compared to the unconstrained structural model. A significant difference was found in the model between the samples (see table 4).

Third, all individual structural relationships were compared across the two samples to identify the specific relationships on which the Danish and Brazilian samples differed. Therefore, invariance tests with chi-square differences were conducted by comparing the unconstrained structural model to each of the constrained structural models having one of the structural relationships set to be invariant (table 4). Significant differences in the $\chi^{2}$ value appeared in three out of four hypothesized relationships (Hypotheses 1, 2, and 4): group relatedness $\rightarrow$ intended interaction, company relatedness $\rightarrow$ intended interaction, and perceived outcome benefits $\rightarrow$ intended interaction. This implies that the strength of these relationships differs significantly between the Danish and the Brazilian sample.

Finally, the conceptual model (figure 1) was tested for the Danish and Brazilian samples individually based on the partially constrained SEM (table 5). Hypotheses 1, 2, and 4 were supported for both groups. Thus, in both Denmark and Brazil, group relatedness, company relatedness, and perceived outcome benefits related positively to intended interaction. H3 was not supported in any sample indicating no significant relationship between perceived skills and intended interaction.

The relationship between group relatedness and intended interaction was significantly higher for the Brazilian sample compared to the weaker relationship in the Danish sample. On the other hand, the relationship between company relatedness and intended interaction was significantly higher in the Danish sample than in the Brazilian sample. Perceived skills indicated no significant influence in any of the samples. The coefficient of perceived outcome benefits was significantly higher for the Danish sample, although the difference was small.

\section{Discussion}

This study investigated how motivation factors, rooted in consumers' psychological need for relatedness, competence, and autonomy, influence their interaction intention in a VC aimed at product innovation together with a company. Focus was specifically on the moderating effect of country in terms of the cultural dimension: individualism-collectivism. Therefore, two samples 
were employed based on this dimension: a Danish sample representing a culture characterized by individualistic values and a Brazilian sample representing a culture characterized by more collectivistic values.

The following discusses the role of relatedness, perceived skills, and perceived outcome benefits in driving intended interaction in a $\mathrm{VC}$ aimed at product innovation. Focus is on how the individualism-collectivism characterizing the two countries can explain the moderation across countries.

\section{The role of relatedness as a main contributor to VC interaction}

The need for relatedness appeared to be the basis for the most important motivation factors for both Danish and Brazilian consumers. Existing research claims that social networks and interaction with companies and consumers contribute to fulfilling the need to belong (Achrol and Kotler 1999; Etgar 2008; Kurikko and Tuominen 2012). The significant influence of both group relatedness and company relatedness highlights the relevance of considering both aspects in VCs for product innovation. Still, the results also indicate a difference in the importance between these two types of relatedness across countries. Culture can be relevant in explaining differences in individuals' motivation (Hofstede 1983b). Whereas group relatedness was a strong determinant for Brazilian consumers' interaction intention, it had relatively low importance among Danish consumers. For the Danish consumers, company relatedness was the strongest determinant for intended interaction, but had lower relevance among Brazilian consumers. This difference aligns with the values characterizing the Brazilian and Danish societies, respectively. The collectivistic value of prioritizing the group above the individual corresponds well with a perceived importance of relating to the $\mathrm{VC}$ as a group of people in Brazil (Algesheimer, Dholakia, and Herrmann 2005; Casaló, Flavián, and Guinalíu 2010). As the social identity theory states, individuals wish to belong to an in-group of similar others (Hogg and Terry 2000; Bagozzi and Dholakia 2006), and for Brazilian consumers, identification with the people forming the $\mathrm{VC}$ is therefore important.
For Danish consumers, living in a highly individualistic culture, group relatedness was less important than relatedness to the company. Company relatedness was the strongest factor for interaction intention suggesting that those who can identify strongly with the company are more interested in participating in VCs aimed at product innovation. This implies that for Danish consumers, it is important that the company has an image and values that they can identify with, and similarly that they can trust the company. This finding is in line with O'Reilly and Chatman (1986) claiming that also organizational identification can reflect the need for affiliation. We argue that this apparent importance of company relatedness, in comparison to group relatedness, reflects consumers' individualistic values. The individual identity in VCs for product innovation becomes more important than social identity, as suggested by Nambisan (2002), and the consumer perceives him-/herself more as an individual contributor to innovation than as a member of the group. Trust as part of relatedness plays an important role in consumers' willingness to interact in the VC. As Franke, Keinz, and Klausberger (2013) suggest, perceived fairness in the collaboration is an important driver for consumers engaging in innovation together with companies. If they can trust and identify with the company, they are more willing to engage in behaviors that benefit this company (O'Reilly and Chatman 1986; Ashforth and Mael 1989; Bhattacharya and Sen 2003). Also for Brazilian consumers, the company aspect of relatedness positively relates to interaction intention, which indicates the importance of the ability to identify with and trust the VC-hosting company however, not to the same extent as for the more individualistic Danish consumers.

\section{The role of perceived skills}

Perceived skills were not significantly related to intended interaction neither among Danish nor Brazilian consumers. As such, these results imply that feeling capable in the domain of product innovation has no impact on consumers' intention to engage in the VC. This would contradict earlier findings on motivation in other areas (e.g., 
Harter 1978; Harter 1982; Klint and Weiss 1987; Van den Broeck et al. 2010), but also in research on self-efficacy in consumer behavior (e.g., Bandura 1982; Kim, Kim, and Hwang 2008). However, a reason may be the measure of the perceived skills undertaken. This study specifically addressed consumers' perceived cooking skills, which is only partly linked to the specific task of developing food products for weight management. Thus, perceived skills within an overall product domain (i.e., food) do not necessarily predict intended interaction for a more specific sub-category of products (i.e., food for weight management). Furthermore, most respondents rated their food preparation skills rather high, which could mean that most of them felt they were capable of the task, and therefore the minor differences in perceived skills were not reflected in the willingness to interact. Perceived skills, that are more specific to those needed in the product innovation task, may be better predictors of interaction intention.

\section{The role of perceived outcome benefits}

Both for Brazilian and Danish consumers, results showed that a perceived beneficial outcome is a driver of the intended interaction. A reason can be found in the role of empowerment (e.g., Etgar 2008; Füller et al. 2009; Mosteller and Mathwick 2014; Martinez-Canas et al. 2016) which corresponds with the basic psychological need for autonomy as a motivation factor (Ryan and Deci 2000). Knowing that one's behavior can provide beneficial outcomes may provide consumers with a feeling of empowerment when they are able to influence the products that are available in the market. The feeling of contributing to a better outcome supporting social well-being may be even more important when considering a product supporting weight management. Martinez-Canas et al. (2016) state that consumers are more willing to engage in product innovation for an outcome benefiting the welfare of society in general.

Results showed that the relationship between the perceived outcome benefits and intended interaction is more important for Danish consumers compared to Brazilian consumers. This may be surprising, as collectivistic values of prioritizing the group over the individual yield an expectation of a collectivistic culture having higher preference for gaining an outcome that benefits consumers and the market. On the other hand, the feeling of empowerment obtained by the individual consumer may correspond well with individualistic values of prioritizing oneself as a consumer. In other words, because consumers perceive the outcome as benefiting themselves as individual consumers, they may be more prone to participate in interaction activities for product innovation based on perceived outcome benefits.

However, it is important to remember that the perceived outcome benefits seem to be a valued factor in both individualistic and collectivistic cultures: both Brazilian and Danish consumers are driven by the opportunity to achieve better outcomes.

Summing up, the results demonstrated relatedness to be, by far, the strongest driver of consumers' intended VC interaction. However, the importance of group vs. company relatedness differed significantly between countries, which is in line with the respective individualistic and collectivistic cultural values characterizing the societies. Furthermore, the possibility of beneficial outcomes for consumers and the market drove consumers in both cultures. Finally, perceived skills within the product domain were not perceived as important when it comes to intention to engage in VC interaction activities in either country.

\section{Implications}

This study adds to the literature on consumer integration in VCs for product innovation by taking the role of culture into account. This research is relevant in order to understand how to organize VCs aimed at consumer integration in innovation in different cultures. This cultural aspect provides some rather interesting managerial implications.

In both cultures, relatedness is the strongest driver of intended VC interaction. However, for the collectivistic Brazilian consumers, relatedness to the VC as a group of people dominated, whereas it was of less importance to the individualistic Danish consumers. As relatedness plays an 
important role in consumers' involvement in intended interaction, this should be a main focus of $\mathrm{VC}$ managers. However, they must be aware of the culture they are operating in, in order to emphasize the right type of relatedness for the consumers. The results indicate that VC's for product innovation may to some extent be perceived as traditional cultural communities, and therefore the culture is reflected in the $\mathrm{VC}$ values preferred by consumers. In other words, the cultural parameter of individualism-collectivism is reflected also in more specific communities (such as an online environment for product innovation) operating within the respective cultures. In collectivistic cultures, managers need to consider the consumers' identification with the community and reflect this in the values signaled from the VC. They must facilitate interaction among members of the community by using group-based incentives to attract peer consumers. The VC must be promoted as a group of fellow consumers. On the other hand, relatedness to the VChosting company must be emphasized in individualistic cultures, although this should not be ignored in collectivistic cultures either. Managers should focus on company relatedness by supporting the feeling of trust in and identification with the company. Thus, peer consumers constituting the VC are less important, whereas the company characteristics should be highlighted, in order to attract potential members. In other words, the company needs to put effort in promoting itself and its values in relation to the VC.

A second important factor in both cultures was the perceived outcome benefits. By showing consumers how their results are used and how they have contributed to the market, they must be ensured that their participation is beneficial. This can be achieved, for example, by regular feedback or open dialog in the community. Consumers need to experience a feeling of influence in shaping the innovation outcome. At the same time, managers should not expect that people with broad skills within the product domain are the most motivated participants in a VC. This suggests that managers should not put resources into attracting people with broad skills, but there may be domain-specific skills that are essential for the capability of contributing to the product innovation task. Balancing between broad domain-specific skills and product-specific skills can be a challenge if the individual members of the VC have to be shifted from one product innovation to another. Defining the skills that are relevant for VC membership is one of the tasks that community managers must contemplate carefully.

\section{Limitations and future research}

By focusing on one specific country-based dimension: individualism-collectivism as a moderating factor, this study took a cultural perspective on companies' integration of consumers in VCs for product innovation. Although, this gave a narrow peek into the moderating role of culture in the willingness to participate in VC based product innovation, our results suggest that studying other cultural dimensions, such as power distance, masculinity, or uncertainty avoidance (Hofstede 1983b), may be highly relevant for understanding differences in the importance of motivation factors. Furthermore, samples from other countries are necessary to support or question the current findings.

Different data collection procedures were chosen in the two samples (online survey and face-to-face-survey) to obtain a representative sample in each country. Using the two different sampling methods may have caused some biases in relation to, for instance, flexibility in participation and interviewer bias. However, obtaining representative samples for both countries on the dimension of age and gender was prioritized to enable a comparison of the two groups.

The selected target product, food for weight management, is likely to have individual and societal relevance in both countries. However, some cultures may be more enthusiastic about food per se compared to others (Tellis, Yin, and Bell 2009). Replicating the study with other types of products would be of interest to see whether the results are generalizable to VCs in other domains. This would enable us to determine how $\mathrm{VC}$ consumer behavior varies in diverse areas of product innovations.

The motivation factors addressed in this study are all rooted in the need for relatedness, 
competence, or autonomy. Better measures related to competence needs such as perceived skills within the specific product innovation task or within general online interaction could be applied. For VCs, online interaction skills may be a relevant aspect of consumers' perceived competence for driving their interaction behavior.

Finally, these results are based on a survey, and results should therefore be interpreted carefully when it comes to causality. To overcome this problem, the conceptual model builds on well-established theory (Ryan and Deci 2000). In relation to that, interaction activity as the dependent variable was addressed as the intentional behavior. Optimally, future research should look at actual behavior by addressing motivation factors among consumers in already existing VCs for product innovation. However, these VCs must be comparable between countries.

\section{Disclosure statement}

No potential conflict of interest was reported by the author(s).

\section{References}

Aaker, J. L., and P. Williams. 1998. Empathy versus pride: the influence of emotional appeals across cultures. Journal of Consumer Research 25 (3):241-61.

Abbasi, M. S., A. Tarhini, T. Elyas, and F. Shah. 2015. Impact of the individualism and collectivism over the individual's technology acceptance behaviour: a multigroup analysis between Pakistan and Turkey. Journal of Enterprise Information Management 28 (6):747-68.

Achrol, R. S., and P. Kotler. 1999. Marketing in the network economy. Journal of Marketing 63 (Special issue):146-63.

Algesheimer, R., U. M. Dholakia, and A. Herrmann. 2005. The social influence of Brand community: Evidence from European car clubs. Journal of Marketing 69 (3):19-34.

Anderson, J. C., and D. W. Gerbing. 1988. Structural equation modelling in practice: a review and recommended two-step approach. Psychological Bulletin 103 (3):411-23.

Ardichvili, A. 2008. Learning and knowledge sharing in virtual communities of practice: Motivators, barriers, and enablers. Advances in Human Resources 10 (4):541-54.

Ardichvili, A., V. Page, and T. Wentling. 2003. Motivation and barriers to participation in virtual knowledge-Sharing Communities of practice. Journal of Knowledge Management 7 (1):64-77.

Ashforth, B. E., S. H. Harrison, and K. G. Corley. 2008. Identifications in organizations: an examination of four fundamental questions. Journal of Management 34 (3): 325-74.

Ashforth, B. E., and F. Mael. 1989. Social identity theory and the organization. Academy of Management Review 14 (1):20-39.

Bagozzi, R. P., and U. M. Dholakia. 2006. Open source software user communities: a study of participation in Linux user groups. Management Science 52 (7):1099-115.

Bandura, A. 1982. Self-efficacy mechanism in human agency. American Psychologist 37 (2):122-47.

Bhattacharya, C. B., and S. Sen. 2003. Consumer-Company Identification: a framework for understanding consumers' relationships with companies. Journal of Marketing 67 (2):76-88.

Bitzer, J., and I. Geishecker. 2010. Who contributes voluntarily to OSS? An investigation among German IT employees. Research Policy 39 (1):165-72.

Casaló, L., C. Flavián, and M. Guinalíu. 2010. Determinants of the intention to participate in online travel communities and effects on consumer behavioral intentions. Tourism Management 31 (6):898-911.

Chang, H. H., and S. S. Chuang. 2011. Social Capital and individual motivations on knowledge sharing: Participant involvement as a moderator. Information \& Management 48 (1):9-18.

Chesbrough, H. 2003. Open innovation: the new imperative for creating and profiting from technology. Boston, MA: Harvard Business School Press.

Chiu, C. M., M. H. Hsu, and E. T. G. Wang. 2006. Understanding knowledge sharing in virtual communities: an integration of social Capital and social cognitive theories. Decision Support Systems 42 (3):1872-88.

Chow, C. W., F. J. Deng, and J. L. Ho. 2000. The openness of knowledge sharing within organizations: a comparative study of the United States and the people's republic of China. Journal of Management Accounting Research 12 (1):65-95.

Cooper, R. G., and E. J. Kleinschmidt. 2007. Winning businesses in product development: the critical success factors. Research Technology Management 50 (3):52-66.

Dahlander, L., and D. M. Gann. 2010. How open is innovation. Research Policy 39 (6):699-709.

Daugherty, T., W. N. Lee, H. Gangadharbatla, K. Kim, and S. Outhavong. 2005. Organizational virtual communities: Exploring motivations behind online panel participation. Journal of Computer-Mediated Communication 10 (4). Retrieved from: https://doi.org/10.1111/j.1083-6101.2005. tb00272.x

David, P. A., and J. S. Shapiro. 2008. Community-based production of open-source software: what do we know about the developers who participate? Information Economics and Policy 20 (4):364-98.

Deci, E. L., and R. M. Ryan. 2000. The "what" and "why" of goal-Pursuits: Human needs and the self-determination of behavior. Psychological Inquiry 11 (4):227-68. 
Dutton, J. E., J. M. Dukerich, and C. V. Harquail. 1994. Organizational images and member identification. Administrative Science Quarterly 39 (2):239-63.

Etgar, M. 2008. A descriptive model of the consumer coProduction Process. Journal of the Academy of Marketing Science 36 (1):97-108.

Fornell, C., and D. F. Larcker. 1981. Evaluating structural equation models with unobservable variables and measurement error. Journal of Marketing Research 18 (1): 39-50.

Franke, N., P. Keinz, and K. Klausberger. 2013. Does this sound like a fair deal?": antecedents and consequences of fairness expectations in the individual's decision to participate in firm innovation. Organization Science 24 (5): 1495-516.

Franke, N., and F. Shah. 2003. How companies support innovative activities: an exploration of assistance and sharing among end-users. Research Policy 32 (1):157-78.

Fuchs, C., and M. Schreier. 2011. Customer empowerment in new product development. Journal of Product Innovation Management 28 (1):17-32.

Füller, J. 2010. Refining virtual co-creation from a consumer perspective. California Management Review 52 (2): 98-122.

Füller, J., G. Jawecki, and H. Mühlbacher. 2007. Innovation creation by online basketball communities. Journal of Business Research 60 (1):60-71.

Füller, J., H. Mühlbacher, K. Matzler, and G. Jawecki. 2009. Consumer empowerment through internet-Based CoCreation. Journal of Management Information Systems 26 (3):71-102.

Greer, C. R., and D. Lei. 2012. Collaborative innovation with customers: a review of the literature and suggestions for future research. International Journal of Management Reviews 14 (1):63-84.

Griffin, A., and A. L. Page. 1996. PDMA success measurement project: recommended measures for product development success and failure. Journal of Product Innovation Management 13 (6):478-96.

Hair, J. F., W. C. Black Jr., B. J. Babin, and R. E. Anderson. 2010. Multivariate data analysis: a global perspective. 7th ed. Upper Saddle River, NJ: Pearson.

Hars, A., and S. Ou. 2002. Working for free? Motivations for participating in open-source projects. International Journal of Electronic Commerce 6 (3):25-39.

Harter, S. 1978. Effectance motivation reconsidered. Human Development 21 (1):34-64.

Harter, S. 1982. The perceived competence scale for children. Child Development 53 (1):87-97.

Hartmann, C., S. Dohle, and M. Siegrist. 2013. Importance of cooking skills for balanced food choices. Appetite 65 :125-31.

Henard, D. H., and D. M. Szymanski. 2001. Why some products are more successful than others. Journal of Marketing Research 38 (3):362-75.

Hertel, G., S. Niedner, and S. Herrmann. 2003. Motivation of software developers in open source projects: an internet-based survey of contributors to the Linux kernel. Research Policy 32 (7):1159-77.

Hofstede-Insights. 2018. Accessed April 11, 2018. www.hofstede-insights.com.

Hofstede, G. 1983a. The cultural relativity of organizational practices and theories. Journal of International Business Studies 14 (2):75-89.

Hofstede, G. 1983b. National cultures in four dimensions: a research-based theory of cultural differences among nations. International Studies of Management \& Organization 13 (1-2):46-74.

Hofstede, G. 1991. Cultures and organizations. Berkshire: McGRAW-HILL Book Company Europe.

Hofstede, G. 2001. Culture's consequences. 2nd ed. Thousand Oaks, CA: Sage.

Hofstede, G., and R. R. McCrae. 2004. Personality and culture revisited: Linking traits and dimensions of culture. Cross-Cultural Research 38 (1):52-88.

Hogg, M. A., and D. J. Terry. 2000. Social identity and selfcategorization processes in organizational contexts. Academy of Management Review 25 (1):121-40.

Hornik, S., and A. Tupchiy. 2006. Culture's impact on technology mediated learning: the role of horizontal and vertical individualism and collectivism. Journal of Global Information Management 14 (4):31-56.

Hsu, C. P., Y. F. Chiang, and H. C. Huang. 2012. How experience-driven community identification generates trust and engagement. Online Information Review 36 (1): 72-88.

Hutter, K., B. A. Nketia, and J. Füller. 2017. Falling short with participation - different effects of ideation, commenting, and evaluating behavior on open strategizing. Long Range Planning 50 (3):355-70.

Jeppesen, L. B., and L. Frederiksen. 2006. Why do users contribute to firm-Hosted User communities? The case of computer-controlled music instruments. Organization Science 17 (1):45-63.

Jeppesen, L. B., and M. J. Molin. 2003. Consumers as codevelopers: learning and innovation outside the firm. Technology Analysis \& Strategic Management 15 (3): 363-83.

Jin, B., J. Y. Park, and J. Kim. 2008. Cross-cultural examination of the relationships among firm reputation, E-satisfaction, E-trust, and E-loyalty. International Marketing Review 25 (3):324-37.

Kim, Y. H., D. J. Kim, and Y. Hwang. 2008. Exploring online transaction self-efficacy in trust building in B2C E-Commerce. Journal of Organizational and End User Computing 21 (1):37-59.

Klint, K. A., and M. R. Weiss. 1987. Perceived competence and motives for participating in youth sports: a test of Harter's competence motivation theory. Journal of Sport Psychology 9 (1):55-65.

Kumar, V. 2014. Understanding cultural differences in innovation: a conceptual framework. Journal of International Marketing 22 (3):1-29. 
Kurikko, H., and P. Tuominen. 2012. Collective value creation and empowerment in an online Brand community: a netnographic study on LEGO builders. Technology Innovation Management Review 2 (6):12-7.

Lee, H. H., and E. Chang. 2011. Consumer attitudes towards online mass customization: an application of extended technology acceptance model. Journal of Computer-Mediated Communication 16 (2):171-200.

Lee, S. M. 1971. An empirical analysis of organizational identification. Academy of Management Journal 14 (2): 213-26.

Luna, D., and S. F. Gupta. 2001. An integrative framework for cross-Cultural Consumer behavior. International Marketing Review 18 (1):45-69.

Lynn, M., and B. Gelb. 1996. Identifying innovative national markets for technical consumer goods. International Marketing Review 13 (6):43-57.

Lüthje, C. 2004. Characteristics of innovating users in a consumer goods field: an empirical study of sport-related product consumers. Technovation 24 (9):683-95.

Madupu, V., and D. O. Cooley. 2010. Cross-Cultural Differences in online Brand communities: an exploratory study of Indian and American online Brand communities. Journal of International Consumer Marketing 22 (4): 363-75.

Markus, H. R., and S. Kitayama. 1991. Culture and the self: implications for cognition, emotion, and motivation. Psychological Review 98 (2):224-53.

Martinez-Canas, R., P. Ruiz-Palomino, J. Linuesa-Langreo, and J. J. Blázquez-Resino. 2016. Consumer participation in co-Creation: an enlightening model of causes and effects based on ethical values and transcendent motives. Frontiers in Psychology 7:1-17 (Article 793):

Mosteller, J., and C. Mathwick. 2014. Reviewer online engagement: the role of rank, well-being, and market helping behavior. Journal of Consumer Marketing 31 (6/ 7):464-74.

Muk, A., C. Chung, and J. Kim. 2014. A cross-National Study of the influence of individualism and collectivism on liking Brand pages. Journal of International Consumer Marketing 26 (2):122-37.

Nakata, C., and K. Sivakumar. 1996. National culture and new product development: an integrative review. Journal of Marketing 60 (1):61-72.

Nambisan, S. 2002. Designing virtual customer environments for new product development: toward a theory. Academy of Management Review 27 (3):392-413.

Nambisan, S., and R. A. Baron. 2009. Virtual customer environments: testing a model of voluntary participation in value co-creation activities. Journal of Product Innovation Management 26 (4):388-406.

Narver, J. C., and S. F. Slater. 1990. The effect of market orientation on business profitability. Journal of Marketing 54 (4):20-35.

Nishikawa, H., M. Schreier, and S. Ogawa. 2013. User-generated versus designer-generated products: a performance assessment at Muji. International Journal of Research in Marketing 30 (2):160-7.

Nov, O. 2007. What motivates wikipedians? Communications of the ACM 50 (11):60-4.

O'Reilly, C., and J. Chatman. 1986. Organizational commitment and psychological attachment: the effects of compliance, identification, and internalization on prosocial behavior. Journal of Applied Psychology 71 (3):492-9.

Oreg, S., and O. Nov. 2008. Exploring motivations for contributing to open source initiatives: the roles of contribution context and personal values. Computers in Human Behavior 24 (5):2055-73.

Oyserman, D. 2015. Identity-based motivation. In Oyserman, D (Ed.) Pathways to success through identityBased Motivation, 1-20. Oxford: Oxford University Press.

Park, C., J. Jun, and T. Lee. 2015. Consumer characteristics and the use of social networking sites. International Marketing Review 32 (3/4):414-37.

Patrick, H., C. R. Knee, A. Canevello, and C. Lonsbary. 2007. The role of need fulfillment in relationship functioning and well-being: a self-determination theory perspective. Journal of Personality and Social Psychology 92 (3):434-57.

Poetz, M., and M. Schreier. 2012. The value of crowdsourcing: Can users really compete with professionals in generating new product ideas? Journal of Product Innovation Management 29 (2):245-56.

Poolton, J., and I. Barclay. 1998. New product development from past research to future applications. Industrial Marketing Management 27 (3):197-212.

Porter, C. E., N. Donthu, W. H. MacElroy, and D. Wydra. 2011. How to foster and sustain engagement in virtual communities. California Management Review 53 (4): $80-110$

Proksch, M., U. R. Orth, and T. B. Cornwell. 2015. Competence enhancement and anticipated emotion as motivational drivers of Brand attachment. Psychology \& Marketing 32 (9):934-49.

Ryan, R., and E. L. Deci. 2000. Intrinsic and extrinsic motivations: Classic definitions and new directions. Contemporary Educational Psychology 25 (1):54-67.

Sawhney, H., G. Verona, and E. Prandelli. 2005. Collaborating to create: the internet as a platform for customer engagement in product innovation. Journal of Interactive Marketing 19 (4):4-17.

Schreier, M., C. Fuchs, and D. W. Dahl. 2012. The innovation effect of user design: Exploring consumers' innovation perceptions of firms selling products designed by users. Journal of Marketing 76 (5):18-32.

Schroer, J., and G. Hertel. 2009. Voluntary engagement in an open web-Based Encyclopedia: Wikipedians and why they do it. Media Psychology 12 (1):96-120.

Shavitt, S., C. J. Torelli, and J. Wong. 2009. Identity-based motivation: constraints and opportunities in consumer research. Journal of Consumer Psychology 19 (3):261-6.

Sorensen, N., and D. Oyserman. 2009. Collectivism, effects on relationships. In Encyclopedia of human relationships, 
eds. H.T. Reis and S.K. Sprecher, 233-236. Thousand Oaks, CA: Sage.

Teichmann, K., N. E. Stokburger-Sauer, A. Plank, and A. Strobl. 2015. Motivational drivers of content contribution to company-versus consumer-Hosted Online communities. Psychology of. Psychology \& Marketing 32 (3): 341-55.

Tellis, G. J., E. Yin, and S. Bell. 2009. Global consumer innovativeness: cross-country differences and demographic commonalities. Journal of International Marketing 17 (2):1-22.

Thompson, F. K., and T. Chmura. 2015. Loyalty programs in emerging and developed markets: the impact of cultural values on loyalty program choice. Journal of International Marketing 23 (3):87-103.

Troy, L. C., T. Hirunyawipada, and A. K. Paswan. 2007. Cross-functional integration and new product success: an empirical investigation of the findings. Journal of Marketing 72 (6):132-46.

Van den Broeck, A., M. Vansteenkiste, H. Witte, B. Soenens, and W. Lens. 2010. Capturing autonomy, competence, and relatedness at work: construction and initial validation of the work-related basic need satisfaction scale. Journal of Occupational and Organizational Psychology 83 (4):981-1002.

von Hippel, E. 2007. Horizontal innovation networks-by and for users. Industrial \& Corporate Change 16 (2): 293-315.
Von Hippel, E., J. P. J. de Jong, and S. Flowers. 2012. Comparing business and household sector innovation in consumer products: Findings from a representative study in the United Kingdom. Management Science 58 (9): 1669-81.

von Krogh, G., S. Haefliger, S. Spaeth, and M. W. Wallin. 2012. Carrots and rainbows: motivation and social practice in open source software development. MIS Quarterly. 36:649-76.

Von Krogh, G., and E. Von Hippel. 2006. The promise of research on open source software. Management Science 52 (7):975-83.

Wasko, M. M., and S. Faraj. 2000. It is what one does: why people participate and help others in electronic communities of practice. Journal of Strategic Information Systems $9(2-3): 155-73$.

Wasko, M. M., and S. Faraj. 2005. Why should I share? Examining social Capital and knowledge contribution in electronic networks of practice. MIS Quarterly 29 (1): 35-57.

Wiertz, C., and K. de Ruyter. 2007. Beyond the call of duty: Why consumers contribute to firm-hosted commercial online communities. Organization Studies 28 (3):347-76.

Witell, L., P. Kristensson, A. Gustafsson, and M. Löfgren. 2010. Idea generation: Customer co-creation versus traditional market research techniques. Journal of Service Management 22 (2):140-59. 